\title{
Epidemiology and control of gonorrhoea in Sheffield
}

\author{
M D TALBOT AND G R KINGHORN \\ From the Department of Genitourinary Medicine, Royal Hallamshire Hospital, Sheffield
}

SUMMARY During the period 1977-83, the fall in the yearly incidence of gonorrhoea in the United Kingdom was greatly exceeded by the fall that occurred in Sheffield $(p<0 \cdot 001)$. This local fall occurred despite a large rise in the yearly number of people with sexually transmitted diseases (STDs) presenting at this clinic, and was associated with falls in the incidence of complications of the disease and ratios of men to women with gonorrhoea, and with significantly improved success in tracing contacts of infected persons $(p<0 \cdot 001)$. Although penicillinase producing strains of Neisseria gonorrhoeae, were rare, the number of local isolates exhibiting relative resistance to penicillin $(\mathrm{MIC} \geqslant 0.3 \mathrm{mg} / \mathrm{l})$ rose significantly $(\mathrm{p}<0.001)$ and were more often isolated from well defined "at risk" groups: homosexual men $(p<0.001)$, patients with repeat infections $(p<0 \cdot 01)$, and people infected outside Sheffield $(p<0 \cdot 05)$. The relevance of these observations in the assessment of control of gonorrhoea and to the development of an antibiotic treatment policy are discussed.

\section{Introduction}

During the 1960s and early 1970 s a rapid increase occurred in the number of new patients with gonorrhoea and other conditions presenting yearly to sexually transmitted disease (STD) clinics in the United Kingdom. Although the national incidence of gonorrhoea reached a peak in 1977, the incidence of other conditions has continued to increase. Penicillinase producing strains of Neisseria gonorrhoeae (PPNG), first recognised in this country in 1976, have now become endemic. ${ }^{1}$

In Sheffield, the incidence of gonorrhoea has mirrored these national trends. The purpose of the study reported here has been to review the quality of control of gonorrhoea in this city and to re-evaluate some traditional variables as measures of control.

\section{Patients and methods}

\section{STUDY POPULATION}

We studied patients attending the department of genitourinary medicine at this hospital. This is a modern, purpose built clinic in a large teaching hospital and is the sole facility dealing with STD in an industrial city with a population of 544000 (in

Address for reprints: Dr M D Talbot, Department of Cienitourinary Medicine, Royal Hallamshire Hospital, Glossop Road. Sheffield S10 2.JF

Accepted for publication 19 November 1984
1977). In 1981 only $48(5 \cdot 8 \%)$ of 828 cases of gonorrhoea diagnosed occurred in patients living outside the city boundaries. Most people in the city who suffer from STD are thought to present to the clinic for management. For example-during the six years $1978-83$ only $111(2 \cdot 2 \%)$ of 5101 cases of gonorrhoea diagnosed in the city's laboratories occurred in patients who did not subsequently present to the clinic (data on file with MDT).

\section{SURVEY METHODS}

We studied retrospectively the SBH 60 statutory reports submitted by this clinic to the Chief Medical Officer for the years 1972-82 inclusive. These reports contain details of the number of cases of gonorrhoea and total new conditions diagnosed yearly in addition to details of contact tracing activity relating to patients with gonorrhoea.

The same diagnostic criteria were used for the entire study period, and the recording of diagnostic data was supervised by the same two full time clerical officers.

For each year of the study we calculated: the proportion of all new conditions formed by cases of gonorrhoea; the ratios of men to women with all new conditions and with gonorrhoea; and the proportion of all sexual contacts of patients with gonorrhoea sought who attended the clinic for investigation.

We reviewed the clinical records of all patients in whom gonorrhoea was diagnosed between 1 January 
and 30 June, 1977 and in the same period in 1983. Data concerning the penicillin sensitivity of gonococcal isolates, which has been routinely performed on all clinical isolates since 1974, were extracted and compared for the two periods. The demographic data of patients in whom gonorrhoea was diagnosed in the first six months of 1983 were correlated with the penicillin sensitivity of the strains isolated from them.

\section{DEFINITIONS}

We defined a patient with a repeat infection as one suffering an episode of infection with gonorrhoea that was preceded by at least one documented gonococcal infection in the calendar year before inclusion in the analysis.

In the definition of "contact action taken" we included any attempt by the health adviser to secure the attendance of a sexual contact. This included attempts in which the "field work" was undertaken by the index patient but supervised by the health adviser. Other means at the disposal of the health adviser were the personal visit, the postal system, or the telephone. We have not included in the definition cases where the sexual contact was already attending this or another clinic or was so casual that an attempt at tracing would have been futile. These definitions have been unchanged since 1974 .

We arbitrarily defined as being less penicillin sensitive those gonococcal isolates that required a minimum inhibitory concentration (MIC) of $\geqslant 0.3 \mathrm{mg} / 1$ of penicillin, as measured by the plate dilution method. ${ }^{2}$ The diagnostic criteria of gonorrhoea have remained unchanged throughout the study period and are described elsewhere. ${ }^{3}$

STATISTICAL ANALYSIS

All of the analyses were made using the $\chi^{2}$ test.

\section{Results}

YEARLY INCIDENCE OF GONORRHOEA AND ITS COMPLICATIONS

Table I shows the yearly incidence of gonorrhoea and of all new conditions at two yearly intervals for the period 1972-82. During the study period: (1) the yearly incidence of gonorrhoea fell by $24 \%$, from 803 to 613. The peak incidence of gonorrhoea occurred in 1977, when there were 1224 cases (651 in men, 573 in women). In 1982 the yearly incidence of gonorrhoea in Sheffield was 113 cases per 100000 population; (2) the yearly incidence of all new conditions rose steadily, by $180 \%$ overall, from 4009 to 11217 ; (3) the proportion of all new conditions formed by cases of gonorrhoea fell from $20 \%$ in 1972 to $5.5 \%$ in $1982(\mathrm{p}<0.001)$; and (4) the ratio of men to women with gonorrhoea fell from 1.34:1 in 1972 to $1 \cdot 10: 1$ in 1982. The corresponding figures for all new conditions were $1 \cdot 48: 1$ in 1972 and $1: 1$ in 1982 .

Of the 651 men diagnosed during 1977 as having gonorrhoea, only $15(2 \cdot 3 \%)$ had had homosexual contact. In contrast, $36(26.7 \%)$ of 135 cases of gonorrhoea diagnosed during January to July 1983 occurred in men who had had recent homosexual contact; of these, 17 infections were rectal and one was pharyngeal. In women suffering from gonorrhoea, rectal infections occurred in up to $50 \%$ and pharyngeal infections in up to $10 \%$ of cases. ${ }^{4}$ Infection of the upper genital tract occurred in 25 $(8.6 \%)$ of 290 women with new cases of gonorrhoea during 1982, a yearly incidence of 9 per 100000 women. Of 7017 live births in the city during the whole of 1982, only one case of gonococcal ophthalmia occurred, an annual incidence rate of $0.01 \%$ live births.

\section{CONTACT TRACING ACTIVITIES}

Table II shows the results of contact tracing activities related to cases of gonorrhoea. Although the number of cases in which contact action was taken dropped from 896 in 1974 to 537 in 1982, which resulted from the falling incidence of gonorrhoea, the proportion of contacts sought who attended rose significantly from $62 \%$ to $92 \%\left(\chi_{1}^{2}=156 ; p<0.001\right)$, as did the proportion of those attending who had gonorrhoea (from $43 \%$ in 1974 to $69 \%$ in $1982\left(\chi_{1}^{2}=86.0\right.$; $\mathrm{p}<0 \cdot 001)$ ).

\section{SENSITIVITY OF GONOCOCCAL ISOLATES TO}

PENICILLIN

Table III shows sensitivity to penicillin of $N$ gonorrhoeae isolated during two corresponding periods of

TABLE I Incidence of gonorrhoea compared with all new conditions in Sheffield in selected years 1972-82

\begin{tabular}{|c|c|c|c|c|c|c|c|}
\hline \multirow[b]{2}{*}{ Year } & \multicolumn{3}{|c|}{ Episodes of gonorrhoea in: } & \multicolumn{3}{|c|}{ All new conditions: } & \multirow[b]{2}{*}{$\begin{array}{l}\text { Cases of gonorrhoea } \\
\text { as } \% \text { of all STDs }\end{array}$} \\
\hline & Men & Women & $\begin{array}{l}\text { Ratio of men } \\
\text { to women }\end{array}$ & Men & Women & $\begin{array}{l}\text { Ratio of men } \\
\text { to women }\end{array}$ & \\
\hline $\begin{array}{l}1972 \\
1974 \\
1976 \\
1978 \\
1980 \\
1982\end{array}$ & $\begin{array}{l}461 \\
512 \\
531 \\
524 \\
461 \\
323\end{array}$ & $\begin{array}{l}342 \\
430 \\
517 \\
417 \\
411 \\
290\end{array}$ & $\begin{array}{l}1 \cdot 34: 1 \\
1 \cdot 19: 1 \\
1 \cdot 02: 1 \\
1 \cdot 26: 1 \\
1 \cdot 10: 1 \\
1 \cdot 10: 1\end{array}$ & $\begin{array}{l}2393 \\
2978 \\
3608 \\
4605 \\
5290 \\
5623\end{array}$ & $\begin{array}{l}1616 \\
2037 \\
2545 \\
3143 \\
4677 \\
5594\end{array}$ & $\begin{array}{l}1 \cdot 48: 1 \\
1 \cdot 46: 1 \\
1 \cdot 42: 1 \\
1 \cdot 46: 1 \\
1 \cdot 13: 1 \\
1 \cdot 00: 1\end{array}$ & $\begin{array}{r}20 \cdot 0 \\
18 \cdot 8 \\
17 \cdot 0 \\
12 \cdot 1 \\
8 \cdot 7 \\
5 \cdot 5\end{array}$ \\
\hline
\end{tabular}


TABLE II Tracing sexual contacts of patients with gonorrhoea in Sheffield during 1974-82

\begin{tabular}{|c|c|c|c|c|c|}
\hline \multirow[b]{2}{*}{ Year } & \multirow[b]{2}{*}{ Cases of gonorrhoea } & \multirow[b]{2}{*}{ Contacts sought } & \multicolumn{2}{|c|}{ Contacts attending (\%) of those sought } & \multirow[b]{2}{*}{ Total } \\
\hline & & & With gonorrhoea & Uninfected & \\
\hline $\begin{array}{l}1974 \\
1976 \\
1978 \\
1980 \\
1982\end{array}$ & $\begin{array}{r}942 \\
1048 \\
941 \\
872 \\
613\end{array}$ & $\begin{array}{l}896 \\
872 \\
728 \\
769 \\
537\end{array}$ & $\begin{array}{l}388(43 \cdot 3) \\
454(52 \cdot 1) \\
332(45 \cdot 6) \\
324(42 \cdot 1) \\
369(68 \cdot 7)\end{array}$ & $\begin{array}{l}169(18 \cdot 9) \\
180(20 \cdot 6) \\
126(17 \cdot 3) \\
149(19 \cdot 4) \\
127(23 \cdot 6)\end{array}$ & $\begin{array}{l}557(62 \cdot 1) \\
634(72 \cdot 7) \\
458(62 \cdot 9) \\
473(61 \cdot 5) \\
496(92 \cdot 4)\end{array}$ \\
\hline
\end{tabular}

TABLE III Sensitivity to penicillin of gonococcal strains isolated in Sheffield during January to June in 1977 and 1983

\begin{tabular}{|c|c|c|c|c|c|}
\hline \multirow[b]{2}{*}{ Year } & \multirow[b]{2}{*}{$\begin{array}{l}\text { No of } \\
\text { strains }\end{array}$} & \multicolumn{3}{|c|}{ No $(\%)$ strains needing MICs ( $\mathrm{mg} / \mathrm{l})$ of penicillin of: } & \multirow[b]{2}{*}{$\begin{array}{l}\text { Total } \geqslant 0 \cdot 3 \\
\text { (less sensitive) }\end{array}$} \\
\hline & & $\begin{array}{l}<0.3 \\
\text { (more sensitive) }\end{array}$ & $0 \cdot 3 \cdot 1 \cdot 2$ & $\begin{array}{l}>I \cdot 2 \\
(\beta \text { lactamase positive*) }\end{array}$ & \\
\hline $\begin{array}{l}1977 \\
1983\end{array}$ & $\begin{array}{l}469 \\
407\end{array}$ & $\begin{array}{l}432 \\
313\end{array}$ & $\begin{array}{l}36 \\
90\end{array}$ & $\begin{array}{l}1(0) \\
4(2)\end{array}$ & $\begin{array}{l}37(7 \cdot 9) \\
94(23 \cdot 1)\end{array}$ \\
\hline
\end{tabular}

MIC = minimum inhibitory concentration.

* penicillinase producing strains.

1977 and 1983. Despite the falling incidence of gonorrhoea, the number and proportion of less sensitive strains (MIC $\geqslant 0.3 \mathrm{mg} / \mathrm{l}$ ) rose from 37 $(7.9 \%)$ in 1977 to $94(23.1 \%)$ in $1983\left(\alpha_{1}{ }^{2}=42\right.$; p $<0.001)$. PPNG strains first appeared in Sheffield during 1979 , but their numbers have remained small. During the whole of 1983 only $8(1 \cdot 2 \%)$ of 677 cases of gonorrhoea were caused by $\beta$ lactamase (penicillinase) producing isolates.

Table IV shows the sensitivity to penicillin of gonococcal strains isolated during the first six months of 1983 correlated with various demographic features of the infected patients. Less sensitive strains were significantly more common in three identifiable groups of patients; those with repeat infections ( $<<0.01)$, homosexual men ( $<<0.001)$, and patients infected outside Sheffield $(p<0 \cdot 05)$. Factors not appreciably associated with the acquisition of less sensitive strains were patients' sex, age, ethnic group, number of previous gonococcal infections, and infections transmitted by casual sexual partners.

\section{Discussion}

The fall in incidence of gonorrhoea in Sheffield between 1977 and 1982 of almost 50\% greatly exceeds the decrease in the national incidence of gonorrhoea. After reaching a peak of 65963 cases in 1977, the national total fell to 58782 in 1982, a decrease of $11 \%$. For the latter years the incidence of gonorrhoea in Sheffield, which is a large industrial city typically associated with a high prevalence of STD, was 113 per 100000 population compared with an overall national incidence of 117 per 100000 population. That this local fall in the incidence of
TABLE IV Sensitivity to penicillin of strains of $N$ gonorrhoeae isolated during January to June 1983 in relation to demographic data of patients

\begin{tabular}{|c|c|c|}
\hline Study group & No tested & $\begin{array}{l}\text { No }(\%) \text { with } \\
M I C \geqslant 0.3 \mathrm{mg} / I\end{array}$ \\
\hline $\begin{array}{l}\text { No of previous episodes: } \\
<2 \\
>5 \\
\text { Infected by casual sexual contacts: }\end{array}$ & $\begin{array}{r}166 \\
15\end{array}$ & $\begin{array}{r}70(42 \cdot 2) \\
7(46 \cdot 7)\end{array}$ \\
\hline $\begin{array}{l}\text { Yes } \\
\text { No }\end{array}$ & $\begin{array}{r}164 \\
58\end{array}$ & $\begin{array}{l}68(41 \cdot 5) \\
26(44 \cdot 8)\end{array}$ \\
\hline $\begin{array}{l}\text { Patients with repeat infections: } \\
\text { Yes } \\
\text { No }\end{array}$ & $\begin{array}{r}43 \\
179\end{array}$ & $\begin{array}{l}24(55 \cdot 8)^{* *} \\
70(39 \cdot 1)\end{array}$ \\
\hline $\begin{array}{l}\text { Sexual orientation of men: } \\
\text { Heterosexual } \\
\text { Homosexual }\end{array}$ & $\begin{array}{l}99 \\
36\end{array}$ & $\begin{array}{l}33(33 \cdot 3)^{* * * *} \\
29(80 \cdot 6)\end{array}$ \\
\hline $\begin{array}{l}\text { Presumed origin of infection: } \\
\text { Sheffield } \\
\text { Elsewhere }\end{array}$ & $\begin{array}{r}148 \\
74\end{array}$ & $\begin{array}{l}56(37 \cdot 8)^{*} \\
38(51 \cdot 4)\end{array}$ \\
\hline
\end{tabular}

$M I C=$ minimum inhibitory concentration.

${ }^{*} p<0.05 ;{ }^{* *} p<0.01 ;{ }^{* * *} p<0.001$.

gonorrhoea is real, and not merely apparent, is indicated by the low complication rates in women and neonates. During 1982, admissions to all Sheffield hospitals for all episodes related to pelvic inflammatory disease totalled 150 , compared with 200 in 1977.

During the same period the total new conditions diagnosed yearly in the clinic have continued to increase substantially, especially among women. We have also seen appreciable increases in the number of men presenting with gonorrhoea who have had homosexual exposure, and in the success of contact tracing. It appears that our efforts to promote awareness of STD in the general population, to encourage early presentation, and to establish a 
closer rapport with people at high risk of STD, especially homosexual men and heterosexuals who have repeated infections, have been beneficial, although we believe that more efficient contact tracing has made the greatest contribution to the dramatic decline in the incidence of gonorrhoea locally.

With regard to other traditional indices of control, we have seen the ratio of men to women with gonorrhoea approach unity, despite a rising number of infections diagnosed in homosexual men, and reach unity for total new conditions diagnosed yearly. Morton has argued the relevance of the ratio of men to women with gonorrhoea in predicting control of the disease. ${ }^{5}$ Our results support his contention, but we believe that encouraging women to attend the clinic, for whatever reason, facilitates good disease control. Jackson and Jephcott suggested that the proportion of resistant gonococcal isolates within a community was a reliable indicator of control of gonorrhoea. ${ }^{6}$ We question the validity of their hypothesis, as in recent years our control of gonorrhoea has improved despite a rising number and proportion of less sensitive gonococcal isolates. Our results show that these isolates occur more commonly in certain defined groups at risk, particularly those with repeat infections and homosexual men. The social and demographic characteristics of patients with repeat infections and their role in the epidemiology of gonorrhoea have been described previously. ${ }^{7}$ A large proportion of less sensitive gonococcal isolates appears to be imported from outside the city, a factor over which we have little control. This is particularly true for homosexual men, who find little entertainment in Sheffield and are often infected in other large nearby conurbations where their recreational needs are better catered for.

Although the number of gonococcal isolates with a high degree of in vitro resistance to penicillin remains low in Sheffield, we are concerned to prevent the establishment of an endemic pool of such strains. An antibiotic policy has been devised whereby treatment of gonorrhoea varies according to the relative risk of an infected patient bearing a le. $j$ sensitive isolate. We suggest that other clinics should define their high risk groups within their local communities and modify their treatment regimes accordingly. National collation of antibiotic sensitivity patterns in gonococcal isolates may also help identify both national trends and local areas that have a high prevalence of resistant infections. Early feedback of this information to all clinics would also facilitate changes in antibiotic policy, which might inhibit dissemination of resistant infections throughout the United Kingdom.

Although continued efforts are being made in Sheffield to further reduce the incidence of gonorrhoea, it may not be possible to reduce this below a certain irreducible minimum. ${ }^{8}$ In view of the continuing rise in incidence of non-gonococcal STD seen in this and other clinics in the United Kingdom, we feel that it is important to apply to such infections the same techniques (good clinical service, first class diagnostic laboratory support, ${ }^{9}$ and diligent contact tracing) that have achieved relative success in controlling gonorrhoea.

\section{References}

1. McCutchan JA, Adler MW, Berrie JRH. Penicillinaseproducing Neisseria gonorrhoeae in Great Britain, 1977-81: alarming increase in incidence and recent development of endemic transmission. Br Med J 1982; 285:357-40.

2. Reyn $A$, Bentzon MW and Ericsson $H$. Comparative investigations of the sensitivity of $N$ gonorrhoeae to penicillin. Acto Path Microbiol Scand 1963;57:235-55.

3. Morton RS. Gonorrhoea. London: W B Saunders, 1977.

4. Kinghorn GR, Rashid S. Prevalence of rectal and pharyngeal infection in women with gonorrhoea in Sheffield. British Journal of Venereal Diseases 1979; 55:408-10.

5. Morton RS. Male:female ratios in the VD clinics of England and Wales. British Journal of Venereal Diseases 1970; 46: 103-5.

6. Jackson DH and Jephcott AE. Penicillin sensitivity of gonococci. An evaluation of monitoring as an index of control. British Journal of Venereal Diseases 1976;52:253-5.

7. Kinghorn GR, Pryce D, Morton RS. Repeated gonorrhoea in Sheffield. The size of the problem, epidemiologic significance and personal characteristics of repeaters. Sex Transm Dis 1982. 9:165-9.

8. Felton WF. A theory of the epidemiology of gonorrhoea. British Journal of Venereal Diseases 1979;55:58-61.

9. Jephcott AE. The laboratory diagnosis of gonorrhoea with particular reference to modern methodology and its influence on patient management. Sheffield: University of Sheffield 1977. M D Thesis. 